\title{
The Application of Ecological Elements of Digital Technology in Construction Industry
}

\author{
Jie Sun \\ College of Civil Engineering and Architecture, Zhejiang University, Hangzhou, China \\ Email: 547114487@qq.com
}

How to cite this paper: Sun, J. (2021) The Application of Ecological Elements of Digital Technology in Construction Industry. Open Journal of Civil Engineering, 11, 14-27.

https://doi.org/10.4236/ojce.2021.111002

Received: January 21, 2021

Accepted: February 15, 2021

Published: February 18, 2021

Copyright $\odot 2021$ by author(s) and Scientific Research Publishing Inc. This work is licensed under the Creative Commons Attribution International License (CC BY 4.0).

http://creativecommons.org/licenses/by/4.0/ (c) (i) Open Access

\begin{abstract}
The application of digital technology in the field of construction is still in its infancy, and the existing concrete framework of digital technology application in the construction industry and the study of applied ecological elements are not enough. The ecological elements of digital technology application in the construction industry are important factors that promote the healthy operation of the entire digital technology application ecosystem. Using grounded theory, we compiled the data of 33 researchers who participated in semistructured interviews, and obtained 4 main categories and 9 sub-categories of ecological elements of digital technology application in the construction industry. Among them, the digital technology application mechanism is the core category of ecological application elements. We also used the Bass model to analyze the application trend of digital technology in the construction industry. In 2040, the number of construction companies applying digital technology will reach $98.66 \%$ of the maximum market potential.
\end{abstract}

\section{Keywords}

Digital Technology in Construction Industry, Ecological Elements, Technology Diffusion, Grounded Theory, Bass Model

\section{Introduction}

The application of digital technology in the construction industry is still in the preliminary stage of development, but this technology is becoming a key area for the future development of the global construction industry [1]. The new generation of information technology includes cloud technology, artificial intelligence technology, Internet of Things technology and virtual reality technology. These technologies are often used to implement digital management and intelligent services for users. The transformation of the digital industry has attracted the 
attention of governments of various countries. Digital technology has received widespread attention in the manufacturing, financial, and Internet industries. However, the application of this technology in the construction field is still in its infancy, and its existing application ecological environment is not yet perfect [2]. In fact, construction enterprises should speed up the application and promotion of digital technologies such as BIM technology, big data technology and intelligent construction technology [3].

The application of digital technology in fields such as intelligent transportation and smart house construction will cause tremendous changes in the construction industry in the future. However, there is no researcher to establish a specific framework of the digital application ecological theory of the construction industry, and no researcher has conducted in-depth research on the application system of digital technology in the construction industry. In order to better promote the application of digital technology in the construction industry and the high-quality development of the construction industry, it is indispensable to study the ecological elements of the application of digital technology in the construction industry. The digital technology application mechanism is the most important part of the applied ecological elements, which is conducive to promoting the success of the industry's informatization and digital transformation. Digital technology will improve the innovation performance of construction companies and give corporate decision-makers the ability to better allocate resources. This will create a smarter construction industry and have a profound impact on the construction industry. However, the existing research on the ecological elements of digital technology application in the construction industry is still incomplete [4]. Therefore, we will use grounded theory to sort out the ecological elements of digital technology application in the construction industry.

Qualitative research, also called qualitative research, is a research strategy different from quantitative research [5]. Qualitative research is characterized by complexity and diversity, and researchers can formulate an open and flexible research process according to research needs [6]. In the research on the digital technology application ecosystem of the construction industry, there is not enough data or information that can be used for reference, so this article uses qualitative analysis to study the digital ecosystem of the construction industry. Grounded theory is a theory put forward by Glaser and Strauss [7]. This theory is a qualitative research method used to construct a theoretical system and which expands new theories through procedural analysis. This kind of theory is very suitable for studying social issues and allows researchers to have a framework of understanding and integration of theories in an emerging field. So we use this theory to construct the digital ecosystem of the construction industry.

This article innovatively applies grounded theory to the construction of the construction industry's digital ecosystem, and on this basis uses Chinese data to analyze the application trend of digital technology in the construction industry. Using qualitative and quantitative analysis, this article creatively sorts 
out the ecological elements of digital technology in the construction industry, and predicts the future application trends of digital technology in China's construction industry. These will greatly promote the construction industry to use digital technology to drive high-quality development, and provide a theoretical basis for promoting the transformation and upgrading of the construction industry.

\section{Data Collection Based on Semi-Structured Interviews}

\subsection{Methodology of Data Collection}

Since there is no existing database for the research on the digital technology ecosystem of the construction industry, and there is no public data available for collection for empirical research on sample statistics, we use interview methods to collect the required data. There are two types of interviews: structured interviews and semi-structured interviews, both of which are methods for researchers to collect qualitative research data. Structured interview is a quantitative research method and a way to obtain results by providing the interviewee with standardized questions. The results of structured interviews are highly reliable, but they also limit the thinking of the interviewees and cause some limitations in the survey results. Semi-structured interviews refer to informal interviews conducted by formulating a bold interview outline for the interviewees. This method has greater flexibility in the specific application process, allowing the interviewee to diverge thinking based on the questions asked. Therefore, we use semi-structured interviews to diverge the thinking of the interviewer to obtain the ecological elements of digital technology application in the construction industry.

The research on the digital technology ecosystem of the construction industry is still at the preliminary stage, and there is no standardized quantitative framework system. This article is still in the stage of qualitative analysis. The use of structured interview research methods will lead to some limitations in the research results and limit the divergence of innovative thinking in this article. Therefore, this article uses semi-structured interviews to interview experts in related fields, and conducts guided questions based on the actual situation of the interviews. Through effective communication with experts, this article has obtained first-hand information related to digital technology in the construction industry.

\subsection{The Information of Interviewers}

The subjects of our research and interviews follow three principles:

1) The interviewees have a relatively deep understanding of digital technology or the field of traditional architecture, and have relevant experience for more than 5 years.

2) The interviewee has a certain degree of prediction on the future development trend of digital technology or construction industry.

3) Interviewees have a certain degree of awareness of government regulations 
and market conditions, and have unique insights into the management of construction companies or digital technology companies.

On the one hand, there are not so many experts who only focus on the field of digital technology in the construction industry. Most experts focus on the direction of interdisciplinary integration. On the other hand, research in the field of digital technology in the construction industry has just started, and there is no public library of experts to contact. Therefore, we mainly selected the interview subjects from experts in the field of information technology, digital technology, smart construction, traditional construction, and government policy makers and executors. These interviewees have established a very close relationship with the digital technology ecosystem of the construction industry. Taking into account the differences in the regions where the experts are located, this article interviewed the experts by telephone, video and on-site interviews.

Through effective communication, 33 experts in different fields participated in semi-structured interviews, and finally 33 useful interview results were sorted and summarized. These 33 experts come from 4 fields: digital technology, smart construction, traditional construction and government. We used snowball sampling to find relevant experts to participate in the semi-structured interviews. The information about all 33 interview participants is presented in Table 1.

\section{Analysis on Ecological Elements}

\subsection{The Concept of Ecological Elements}

The concept of ecosystem comes from natural sciences. Tansley first proposed the definition of ecosystem, and he believed that an ecosystem is a system formed by the organic combination of organisms and the environment in a certain space in nature. Ecological elements refer to important elements in the ecosystem, and refer to the sum of natural elements closely related to humans. The construction industry digital technology application ecosystem refers to a system in which various participants cooperate with each other during the application and promotion of digital technology in the construction industry to promote the healthy operation of the entire digital technology application ecology. The ecological element of digital technology application in the construction industry refers to an important element that promotes the benign operation of the entire digital technology application ecosystem during the application and promotion of digital technology in the construction industry. In the era of Industry 4.0, the arrival of the $5 \mathrm{G}$ era means that digital technology will bring a higher degree of interactivity to construction companies. That is, the interactivity between enterprises and the social environment will increase. The application of digital technology in construction companies such as the transportation industry and housing construction industry also shows a large degree of diversity and complexity. Its application in construction companies requires different digital solutions based on different scene characteristics. 
Table 1. The list of interviews.

\begin{tabular}{|c|c|c|c|}
\hline Field & Number & Experience (Year) & Position \\
\hline $\begin{array}{c}\text { Digital } \\
\text { Technology }\end{array}$ & 13 & $10-20$ & $\begin{array}{c}2 \text { directors and } 1 \text { consultant of software company, } \\
2 \text { directors and } 1 \text { consultant of hardware company, } \\
2 \text { directors of IT company, } \\
1 \text { analyst of IT company strategic, } \\
4 \text { professors in the field of computer science. }\end{array}$ \\
\hline $\begin{array}{c}\text { Smart } \\
\text { Construction }\end{array}$ & 9 & $15-20$ & $\begin{array}{c}1 \text { chief engineer of smart construction site project, } \\
1 \text { manager of smart parking lot project, } \\
1 \text { supervisor of building intelligent equipment company, } \\
1 \text { supervisor of building intelligent software company } \\
2 \text { consultants of building intelligent company, } \\
2 \text { experts in the field of intelligent transportation, } \\
1 \text { technical supervisor of a building performance intelligent inspection company. }\end{array}$ \\
\hline $\begin{array}{c}\text { Traditional } \\
\text { Construction }\end{array}$ & 5 & $5-15$ & $\begin{array}{l}1 \text { CEO of construction company, } \\
2 \text { directors of engineering department of construction company, } \\
1 \text { CEO of real estate company, } \\
1 \text { consultant of real estate technology. }\end{array}$ \\
\hline government & 6 & $15-25$ & $\begin{array}{c}3 \text { makers of smart city policies, } \\
1 \text { makers of smart transportation policies, } \\
2 \text { makers of traditional building policies. }\end{array}$ \\
\hline
\end{tabular}

In summary, the digital technology application system of the construction industry has the characteristics of interaction, diversity and complexity. These characteristics are similar to the characteristics of interaction, diversity and complexity in the ecosystem. Therefore, analyzing the ecological elements of the application of digital technology in the construction industry will help the promotion and application of digital technology in the construction industry, thereby promoting the high-quality development of the construction industry.

\subsection{Analysis Based on Grounded Theory}

\subsubsection{The Concept of Grounded Theory}

The core process of grounded theory is to encode and re-decompose the original data, and to categorize and reorganize concepts. In this process, the collected data will be summarized and a systematic theory can be constructed. Grounded theory coding includes three steps: Open coding, Axial coding and Selective coding.

With the expansion of the influence of grounded theory in the field of social sciences, grounded theories have been widely used in the establishment of some new theories and models. Some researchers have initially applied grounded theory in the field of digital technology, but grounded theory has not yet been sufficiently applied in the research on the application elements of digital technology in the construction industry. At the same time, with regard to the analysis of digital ecological elements of the construction industry, there is currently no very mature quantitative system and a lack of mature variable categories. Moreover, according to field surveys and semi-structured interviews in this ar- 
ticle, different people have different views on the digital understanding of the construction industry. Therefore, this article innovatively applies the grounded theory to the exploration of the ecological elements of the construction industry's digital technology, and builds a preliminary framework for the application of digital technology in the construction industry.

\subsubsection{Open Coding}

Open coding is the first step to coding. This step gradually conceptualizes the collected original data and unearths similar concepts and connotations in the primary data into categories. This article uses MAXQDA software to sort out the original interview manuscripts of the expert interviews, and code the content of the interview manuscripts. The effective manuscript of 33 experts is about 55,000 words. In order to reduce the prejudice generated by the impression of interviewees, we sorted out the collected materials according to the questions and rearranged the order of sentences in the materials. We obtained a total of 197 initial categories after open coding. After further sorting out the initial concept, the tags with more than three frequencies were extracted and summarized into the initial category. We deleted some inconsistent tags. The demonstration of the initial concept is shown in Table 2.

\subsubsection{Axial Coding}

Axial coding is the excavation of the internal logic and connections between categories on the basis of open coding, and it is a process of abstracting, generalizing and summarizing the main category and the sub-category. We continue to compare and analyze the initial concepts based on open coding, and establish associations between subcategories. Then, we further refined the main category of ecological elements of digital technology application in the construction industry. On the basis of summarizing the initial categories, we through the logical analysis and combing of different initial categories, we get 4 main categories and 9 sub-categories as follows. Among them, the four main categories are policy strategies, management methods, application basis and market environment. The 9 sub-categories are strategic support, policies and regulations, reward and punishment mechanism, standardized management and control, integrated information system, technical foundation, talent foundation, application atmosphere and competitive situation. The main category and the corresponding sub-category are presented in Table 3.

\subsubsection{Selective Coding}

Selective coding is to explore the connection relationship between categories on the basis of the results of spindle coding. This step will eventually form the relationship between the core category and other categories, and build a new theoretical system. We further analyzed the results of Axial coding and found that the digital technology application mechanism is the core category of the ecological elements of digital technology application in the construction industry. The 
digital technology application mechanism is an important part of the digital technology ecosystem of the construction industry, and is a further refinement of the four main categories. The four main categories can be summarized as the core category of construction industry application mechanism, which is also the most important part of the research on the construction industry digital technology ecosystem. The result of our selective encoding is shown in Figure 1.

Table 2. Demonstration of the initial concept.

\begin{tabular}{|c|c|c|}
\hline Number & Initial category & Initial concept \\
\hline \multirow{3}{*}{1} & \multirow{3}{*}{$\begin{array}{l}\text { Industry } \\
\text { planning }\end{array}$} & $\begin{array}{l}\text { The government can give a } 5 \text {-year or } 10 \text {-year industry plan regularly to guide construction companies to } \\
\text { follow the national strategy to apply some emerging information technology. (a1) }\end{array}$ \\
\hline & & $\begin{array}{l}\text { Industry planning is relatively important and it can have some impact on the future development of the } \\
\text { industry. (a2) }\end{array}$ \\
\hline & & $\begin{array}{l}\text { Some industry prospect plans issued by the government still have a certain guiding role for enterprises. } \\
\text { (a3) }\end{array}$ \\
\hline \multirow{3}{*}{2} & \multirow{3}{*}{$\begin{array}{l}\text { Tax } \\
\text { regulations }\end{array}$} & $\begin{array}{l}\text { This policy can promote the application of digital technology by reducing taxes on construction companies } \\
\text { that apply digital technology to reduce the cost of digital technology. (a4) }\end{array}$ \\
\hline & & $\begin{array}{l}\text { The state's reduction of taxes for construction technology innovation enterprises can indeed stimulate our } \\
\text { enthusiasm for research and development. (a5) }\end{array}$ \\
\hline & & $\begin{array}{l}\text { The profit rate of the construction industry is relatively low. When the state lowers taxes for innovative } \\
\text { construction companies, we will also promote R\&D and innovation of companies for tax incentives. (a6) }\end{array}$ \\
\hline \multirow{3}{*}{3} & \multirow{3}{*}{$\begin{array}{l}\text { Local } \\
\text { regulations }\end{array}$} & $\begin{array}{l}\text { Some local governments can use some local regulations and policy dividends to guide local construction } \\
\text { companies to apply new information technology applications. (a7) }\end{array}$ \\
\hline & & Sometimes policies and regional regulations do have some influence on regional companies. (a8) \\
\hline & & $\begin{array}{l}\text { Local regulations will affect the decision-making of local companies, as well as the application of internal } \\
\text { technology in the company's digital technology. (a9) }\end{array}$ \\
\hline \multirow[t]{2}{*}{$\cdots \cdots$} & \multirow[t]{2}{*}{$\cdots \cdots$} & $\cdots \cdots$ \\
\hline & & $\begin{array}{l}\text { If we have good enough hardware technology, our construction companies are also willing to adopt digital } \\
\text { technology to improve their production efficiency. (a611) }\end{array}$ \\
\hline \multirow[t]{2}{*}{195} & \multirow{2}{*}{$\begin{array}{l}\text { Hardware } \\
\text { technology }\end{array}$} & $\begin{array}{l}\text { The application of digital technology in construction enterprises is related to the level of hardware technology. } \\
\text { (a612) }\end{array}$ \\
\hline & & $\begin{array}{l}\text { The domestic hardware technology is decent, and we are more willing to adopt domestic digital software. } \\
\text { (a614) }\end{array}$ \\
\hline \multirow{3}{*}{196} & \multirow{3}{*}{$\begin{array}{l}\text { Standardized } \\
\text { platform }\end{array}$} & $\begin{array}{l}\text { Construction companies can better manage and apply digital technologies by building standardized platforms. } \\
\text { (a615) }\end{array}$ \\
\hline & & $\begin{array}{l}\text { As an information company, we have adopted a standardized platform, thus improving work efficiency. } \\
\text { (a617) }\end{array}$ \\
\hline & & $\begin{array}{l}\text { We have inspected companies in the industry that adopt standardized platforms, and it really makes us more } \\
\text { convenient. (a618) }\end{array}$ \\
\hline \multirow{3}{*}{197} & \multirow{3}{*}{$\begin{array}{l}\text { Vicious } \\
\text { competition }\end{array}$} & $\begin{array}{l}\text { Our information company will encounter vicious competition when promoting some technologies, which will } \\
\text { lead to decreasing the return of technology. (a619) }\end{array}$ \\
\hline & & $\begin{array}{l}\text { I think that guiding the market in a reasonable way to reduce vicious competition can promote the application } \\
\text { of digital technology in construction companies. ( } a 620)\end{array}$ \\
\hline & & $\begin{array}{l}\text { When vicious competition is suppressed and the degree of industry involution is reduced, the atmosphere of } \\
\text { innovation will become better. (a621) }\end{array}$ \\
\hline
\end{tabular}


Table 3. The main category and the corresponding sub-category formed by Axial coding.

\begin{tabular}{|c|c|c|}
\hline Main category & Sub-category & Initial category \\
\hline \multirow[b]{2}{*}{ Policy strategy } & Strategic support & Industry planning, industry outlook, strategic research, prospect planning \\
\hline & Policies and regulations & $\begin{array}{l}\text { Tax regulations, policy guidance, local regulations, legal regulations, government } \\
\text { documents }\end{array}$ \\
\hline \multirow{3}{*}{$\begin{array}{l}\text { Management } \\
\text { method }\end{array}$} & Incentive mechanisms & $\begin{array}{l}\text { Evaluation mechanism, performance evaluation, reward mechanism, punishment } \\
\text { mechanism }\end{array}$ \\
\hline & Standardized control & $\begin{array}{l}\text { Standardized process, standardized management, standardized supervision, standardized } \\
\text { platform }\end{array}$ \\
\hline & Information Integrated $\mathrm{S}$ & Paperless office, information management system, information integrated platform \\
\hline $\begin{array}{l}\text { Application } \\
\text { basis }\end{array}$ & Technical foundation & $\begin{array}{l}\text { Hardware technology, software technology, network technology, } 5 \mathrm{G} \text { technology, blockchain } \\
\text { technology }\end{array}$ \\
\hline \multirow{2}{*}{$\begin{array}{l}\text { Market } \\
\text { environment }\end{array}$} & Application atmosphere & New technology adoption rate, current status of technical barriers, application threshold \\
\hline & Competitive situation & Reasonable competition, vicious competition, healthy competition, competitive situation \\
\hline
\end{tabular}

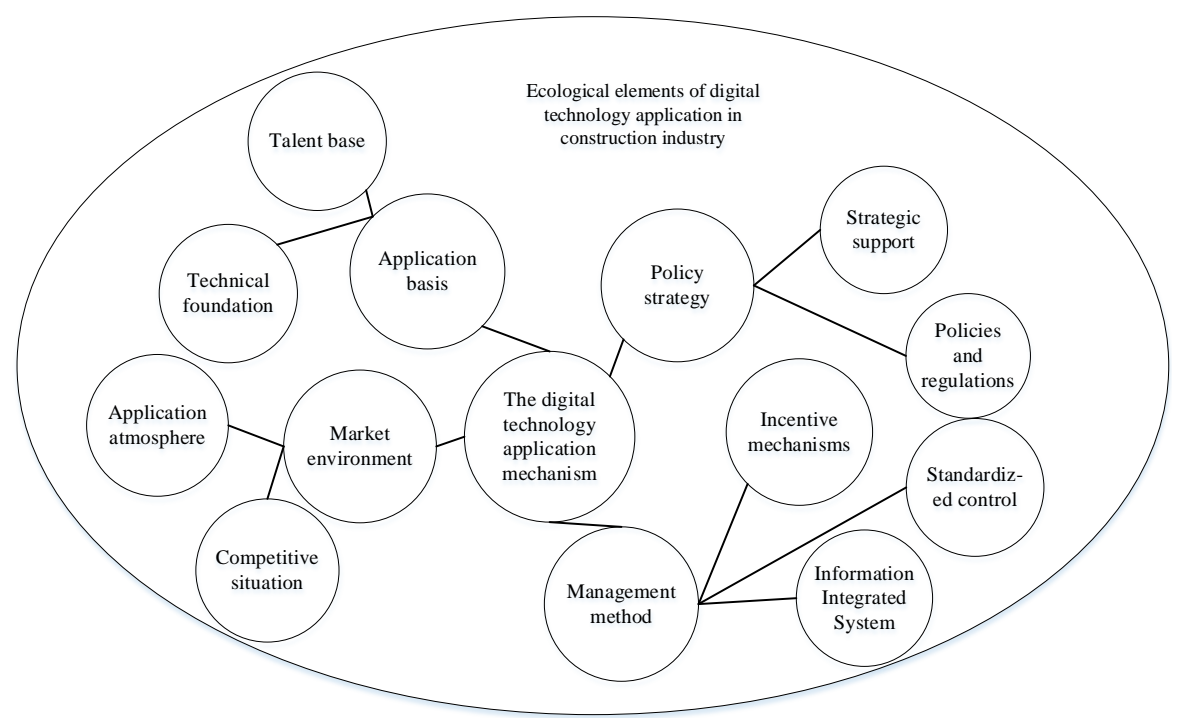

Figure 1. Ecological elements of digital technology application in construction industry.

From the further analysis of the original data, it can be obtained that the core category of the construction industry technology ecological elements is the digital technology application mechanism, and the foundation of technology application, government strategies, management methods and market environment are all included in this core category. Technical foundation and talent foundation are the prerequisites for the application of technology in the construction industry, as well as an important condition for the spread of digital technology. The government's strategic plan for the promotion of digital construction in the construction industry and policies and regulations to promote the application of digital technology in the construction industry will promote the further application of digital construction in the construction industry. At the same time, a 
good technology application atmosphere and a market environment under a reasonable competitive situation are also an important part of the digital technology application mechanism. In the process of the spread of digital technology in the construction industry, construction companies will carry out a series of changes in corporate management in order to better utilize digital technology to improve corporate efficiency. Among them, the reward and punishment mechanism, standardized management and control, and integrated information system will be an important part of the transformation of corporate management.

\subsubsection{Theoretical Saturation Test}

Using grounded theory to analyze the ecological elements of digital technology application in the construction industry requires testing the theoretical saturation. We conducted semi-structured interviews with 6 experts outside the interviews to further the theory of the digital technology ecosystem in the construction industry constructed in this article test. After collating the results of interviews with experts, the results show that the category connotations in the digital technology ecosystem of the construction industry are relatively rich and there are no more initial concepts and categories. It can be seen that the connotation of the ecological element analysis of the application of digital technology in the construction industry has reached saturation.

\section{Analysis of Digital Application Trend in Construction Industry}

\subsection{Model Introduction}

It can be obtained from the theoretical framework of the digital technology ecosystem in the construction industry. The application mechanism of digital technology is the core category of the system. Therefore, we will further analyze the future trend of digital technology application in the construction industry. The application of digital technology occupies a pivotal position in the digital ecological technology of the construction industry. After building a digital technology ecosystem in the construction industry, we will further explore the promotion and application of the most important digital technology in the system in the construction industry. We will take China as an example to analyze the digital technology diffusion trend of construction companies.

The Bass model, Gompertz model, and Logistic model are commonly used models to predict the trend of technological innovation diffusion. These three models are more classic models for studying innovation diffusion. Among these three models, the Bass model is most widely used in the study of technology diffusion [8]. Because of the three parameters in the Bass model, M (market potential), p (innovation coefficient), and $\mathrm{q}$ (imitation coefficient) all have practical significance. The future diffusion trend of the product can be obtained through the analysis of the three parameters. Therefore, we innovatively use the Bass 
model to predict the trend of innovation and diffusion of digital technology products in the construction industry.

The basic form of the Bass model is as follows:

$$
\frac{\mathrm{d} N(t)}{\mathrm{d} t}=\left[p+\frac{q}{M} N(t)\right] \times[M-N(t)][9]
$$

where $p$ represents the innovation coefficient, that is, external factors. $Q$ represents the imitation coefficient, that is, the internal influence factor. $N(t)$ is the cumulative number of enterprises adopting new technology at time $t . M$ is the largest market potential for technology adopters.

\subsection{Parameter Estimation}

\subsubsection{Potential Market Estimation}

The popularization of digital technology in construction companies needs a long period of time. Here, this article will analyze and model the past data to obtain the parameters needed in the Bass model. With the continuous development of the construction industry, more and more construction companies have begun to appear. By sorting the number of construction companies in chronological order, this article constructs a time series of the number of Chinese construction companies collected from 2000 to 2019 [10]. We organize the collected data into pictures and display them in Figure 2. We use the damped Holt method to predict the number of construction companies in 2040. In the case of a damping coefficient of 0.1 , we use python loop iteration to predict next year's data using the quadratic exponential smoothing method. Finally, the total number of construction companies in 2040 is about 152,973. Through expert prediction and analysis, in 2040, the digitalization rate of the construction industry will reach $85 \%$. Therefore, the maximum market potential value $\mathrm{M}$ takes the value of 130,027 .

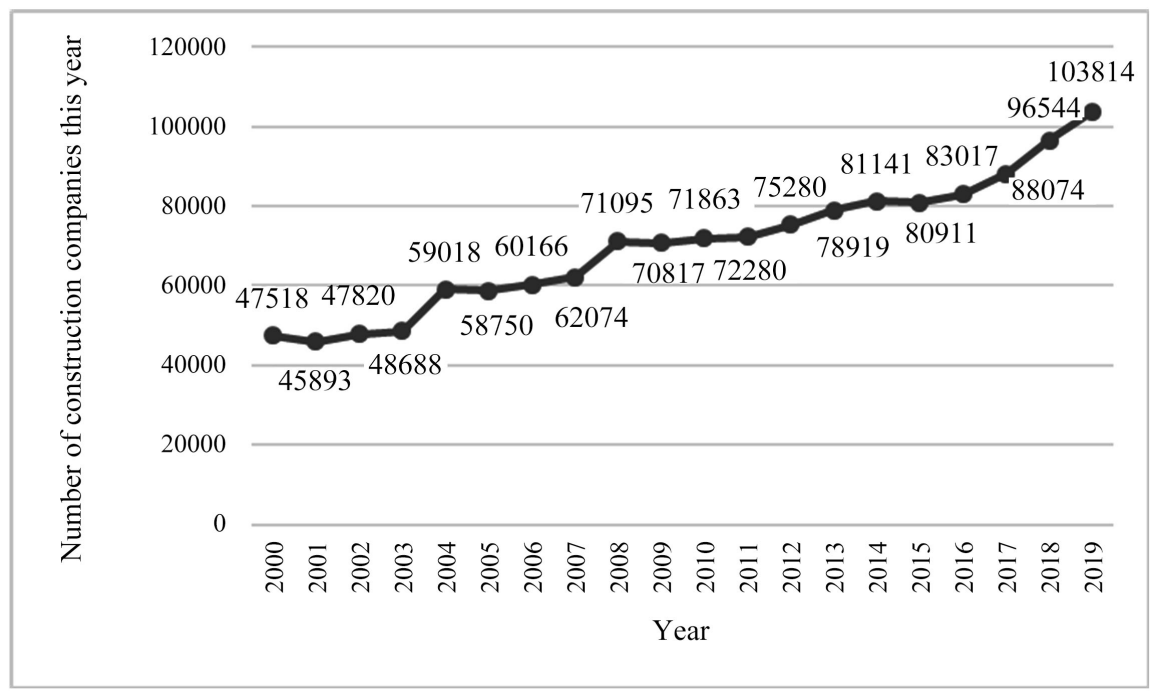

Figure 2. Number of construction enterprises in each year from 2000 to 2019 [10]. 


\subsubsection{Innovation Coefficient and Imitation Coefficient Estimation}

In the public database and public information, we did not find data that can be directly applied, and there is no authoritative expert to estimate the digital technology innovation coefficient and imitation coefficient of the construction industry. Therefore, we selected 18 papers using the Bass model to analyze technology diffusion from 529 papers related to technology diffusion in the Internet field, computer technology field, and digital technology diffusion in the construction industry. We obtain parameter estimates by averaging the collected data. The samples we obtained are as Table 4.

From 18 papers related to the diffusion of digital technology in the construction industry, we selected a total of 23 samples of innovation coefficient $\mathrm{p}$ and imitation coefficient q parameters. Among these digital technology innovation diffusion parameters, the innovation coefficient $\mathrm{p}$ is relatively small, and its value ranges from 0.00050 to 0.13270 . The imitation coefficient $\mathrm{q}$ is relatively large, and its value ranges from 0.00031 to 0.65900 . Taking the average of all $p$ and $q$ parameters, we get the $p$ value of 0.02169 and $q$ value of 0.33107 in the digital technology diffusion of the construction industry.

\subsubsection{Forecast of Digital Technology Application in China's Construction Industry}

In 2003 and 2011, the Ministry of Housing and Urban-Rural Development of China did not have clear guidance on the collaborative application of digital technology in the construction industry. In 2016, the Ministry of Housing and Urban-Rural Development of China emphasized that the construction industry needs to enhance the application of digital technologies such as BIM, big data,

Table 4. Bass model parameter estimation.

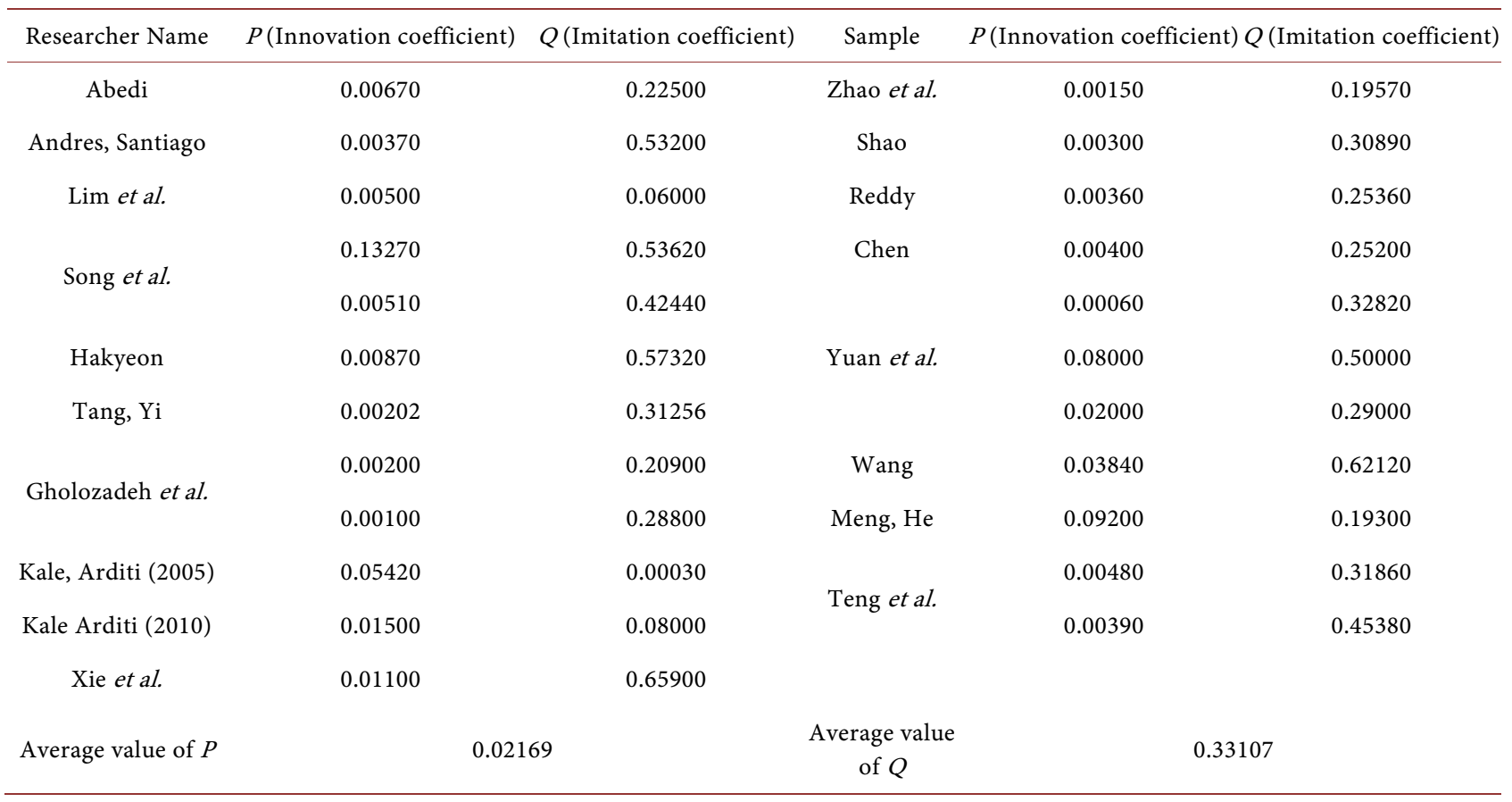




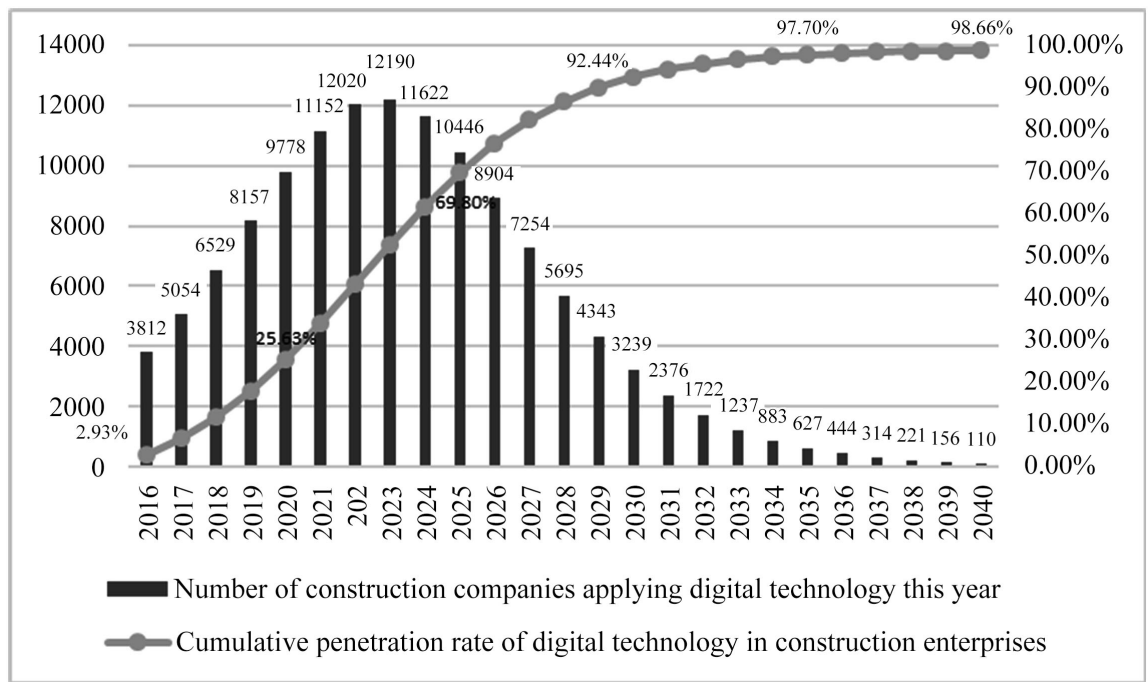

Figure 3. Cumulative penetration rate of digital technology in construction enterprises from 2016 to 2040 .

mobile communications and the Internet of Things in the construction industry. Therefore, we regard 2016 as the starting year for the promotion of ecological application of digital technology in the construction industry. In the Bass model, we substitute $M=130027, p=0.02169$, and $q=0.33107$ into the formula. Using Python calculation results and processing the calculation results, we can get the following results of the digital technology diffusion trend in the construction industry as Figure 3.

We divide the predicted value obtained by the maximum market potential to obtain the penetration rate of digital technology in the construction industry. Judging from the predicted value, the largest number of applications of construction companies using digital technology that year will peak in 2023. After 2023, the annual increase in the number of construction companies applying digital technology will gradually decrease. After the cumulative penetration rate of digital technology in the construction industry reaches $92.44 \%$ in 2030 , the growth rate of the penetration of digital technology in the construction industry will continue to slow down, and in 2040 it reached $98.66 \%$ of the maximum market potential annually.

\section{Conclusion}

The continuous development of information technology and digital technology has brought more opportunities and challenges to the development of the construction industry, which also puts forward stricter requirements on the digital ecological environment of the construction industry to a certain extent. However, the research on the digital ecology of the construction industry is still in its infancy at this stage, and systematic research results have not yet been formed. In order to better promote the further application of digital technology in the construction industry and promote the high-quality development of the con- 
struction industry, we invited 33 experts in the fields of digital technology, smart construction, traditional construction, government and other related fields to carry out the framework of the construction industry digital technology ecosystem. Semi-structured interviews with participants were the main data source in this study. We applied grounded theory and used MAXQDA software to systematically code the results of semi-structured interviews, after open coding, axial coding and selective coding. We finally get that the digital technology diffusion mechanism is the core category of the digital technology ecosystem in the construction industry. The application mechanism of digital technology in the construction industry refers to the process of digital technology in the construction industry, from research and development to promotion, and then to universal application. The Bass model is an important model in predicting the spread of technology. Not only is the calculation method simple, but also its prediction results are also more accurate in practical applications. Therefore, we use the Bass model to predict the future spread of digital technology in the construction industry. We use literature to sort out the estimated parameters related to digital technology. The peak annual increase of construction companies applying digital technology will reach 2023, and the application rate of digital technology in the construction industry will reach $98.66 \%$ of the maximum market potential in 2040 .

\section{Conflicts of Interest}

The author declares no conflicts of interest regarding the publication of this paper.

\section{References}

[1] Ibem, E.O. and Laryea, S. (2014) Survey of Digital Technologies in Procurement of Construction Projects. Automation in Construction, 46, 11-21. https://doi.org/10.1016/j.autcon.2014.07.003

[2] Bilal, M., et al. (2016) Big Data in the Construction Industry: A Review of Present Status, Opportunities, and Future Trends. Advanced Engineering Informatics, 30, 500-521. https://doi.org/10.1016/j.aei.2016.07.001

[3] Boland Jr., R.J., Lyytinen, K. and Yoo, Y. (2007) Wakes of Innovation in Project Networks: The Case of Digital 3-D Representations in Architecture, Engineering, and Construction. Organization Science, 18, 631-647. https://doi.org/10.1287/orsc.1070.0304

[4] Merschbrock, C. and Munkvold, B.E. (2015) Effective Digital Collaboration in the Construction Industry-A Case Study of BIM Deployment in a Hospital Construction Project. Computers in Industry, 73, 1-7. https://doi.org/10.1016/j.compind.2015.07.003

[5] Barbour, R. (2008) Introducing Qualitative Research. Sociology the Journal of the British Sociological Association, 10, 132-133.

[6] Anderson, C. (2010) Presenting and Evaluating Qualitative Research. American Journal of Pharmaceutical Education, 74, 141. https://doi.org/10.5688/aj7408141

[7] Strauss, A.L. and Corbin, J.M. (1997) Grounded Theory in Practice. Contemporary 
Sociology, 28, 296.

[8] Kanniainen, et al. (2011) Forecasting the Diffusion of Innovation: A Stochastic Bass Model with Log-Normal and Mean-Reverting Error Process. IEEE Transactions on Engineering Management, 58, 228-249. https://doi.org/10.1109/TEM.2010.2048912

[9] Satoh, D. (2017) A Discrete Bass Model and Its Parameter Estimation. Journal of the Operations Research Society of Japan, 44, 1-18.

https://doi.org/10.15807/jorsj.44.1

[10] CSY (2019) China Statistical Yearbook. China Statistical Publishing House, Beijing. https://data.stats.gov.cn/easyquery.htm?cn = C01 